\title{
UM POUCO DE GESSO, MUITO DESENHO, TODA A ABNEGAÇÃO: A INSTRUÇÃO DOS OFÍCIOS PARA OS ALUNOS-OPERÁRIOS DO SÉCULO XIX
}

\author{
A little plaster, a lot of design, all abnegation: the instruction \\ of crafts for the 19th century student workers
}

Un poco de yeso, mucho dibujo, toda la abnegación: la formación artesana para estudiantes obreros en el siglo XIX

\section{António Henriques ${ }^{\alpha}$}

Data de receção: 08/08/2020 • Data de aceitação: 03/09/2021

Resumo. O pensamento, escrita e ação do mais informado perito oitocentista português sobre o ensino artístico, e grande conhecedor dos tesouros artísticos de Portugal, o historiador e pedagogo Joaquim de Vasconcelos (1849-1936), orientam-nos na indagação sobre os fundamentos da luta pelo estabelecimento no país do ensino elementar técnico com base na disciplina de desenho, pela dignificação das artes decorativas e pelo estabelecimento de museus de artes industriais.

Esse movimento, inicialmente assumido pela Inglaterra através do Museu de South Kensington, com ramificações centrais em França, na Alemanha e na Áustria, circunscreve a necessidade de dar trabalho às crianças e jovens das classes operárias, na segunda metade do século XIX, proporcionando autonomia, dignidade e fuga à miséria. O que começa por ser uma revolução do ensino do desenho terá grandes consequências na valorização da herança cultural, patrocinada pelas aristocracias e burguesias europeias; e na vontade de a devolver às massas, como efeito de poder das classes dirigentes.

$\mathrm{O}$ artigo discute como essa revolução, e o fomento das artes caseiras, implicaram: i) uma ideação de um património nacionalista, sustentada

\footnotetext{
${ }^{\alpha}$ Unidade de Investigação e Desenvolvimento em Educação e Formação/Instituto de Educação, Universidade de Lisboa (UIDEF/IE-ULisboa). Alameda Universidade, 1649-013, Lisboa, Portugal. antenriques@gmail.com (D) https://orcid.org/0000-0003-0524-6395
}

Como citar este artigo: Henriques, António. «Um pouco de gesso, muito desenho, toda a abnegação: a instrução dos ofícios para os alunos-operários do século XIX». Historia y Memoria de la Educación 15 (2022): 421-450 
num movimento internacional de países; ii) uma autenticação, pelas aristocracias europeias, das chamadas «artes maiores», para servirem de inspiração ao trabalho oficinal; iii) o início do tema da herança cultural como fenómeno de massas populares; iv) a eventual quebra do valor de autenticidade das peças artísticas.

Palavras-chave: Joaquim de Vasconcelos; Arte e ciência aplicada à indústria; Herança cultural; Ensino técnico.

Abstract. The thoughts, writings, and actions of the most informed Portuguese expert on artistic education of the 19th century and connoisseur of Portugal's artistic treasures, the historian and pedagogue Joaquim de Vasconcelos (18491936), guide us in our inquiry into the tenets of the struggle for the establishment of technical elementary schools and industrial art schools based on the discipline of drawing. This struggle for the dignification of decorative arts also promoted the establishment of art-industrial museums.

This movement, initially assumed by England through the South Kensington Museum, and which had ramifications in France, Germany, and Austria, outlined the need to provide work for working class children and youth in the second half of the 19th century and to provide them with autonomy, dignity, and an escape from misery. What began as a revolution in the teaching of drawing would have major consequences for the appreciation of cultural heritage and its sponsorship by the European aristocracy and bourgeoisie, as well as in the will to return it to the masses, as an effect of the power of the ruling classes.

The article discusses how this revolution, and the promotion of homemade arts, implied: i) an ideation of a nationalist heritage, supported by an international movement of countries; ii) a validation of the fine arts by the European aristocracies, to serve as inspiration for craftwork; iii) the beginning of the awareness of cultural heritage as a phenomenon of the popular masses; iv) the alleged fall of the authenticity value of the artistic pieces.

Keywords: Joaquim de Vasconcelos; Art and science applied to industry; Cultural heritage; Technical education.

Resumen. El pensamiento, escritura y acción del experto portugués más informado del siglo XIX en educación artística, y gran conocedor de los tesoros artísticos de Portugal, el historiador y pedagogo Joaquim de Vasconcelos (1849-1936), nos guían en la indagación sobre los fundamentos de la lucha por el establecimiento en el país de la educación técnica primaria basada en la disciplina del dibujo, por la dignificación de las artes decorativas y por el establecimiento de museos de artes industriales.

Este movimiento, inicialmente asumido por Inglaterra a través del Museo South Kensington, con ramificaciones centrales en Francia, Alemania y 
Austria, circunscribe la necesidad de proporcionar trabajo a los niños y jóvenes de las clases trabajadoras en la segunda mitad del siglo XIX, proporcionando autonomía, dignidad y escape de la miseria. Lo que comienza como una revolución en la enseñanza del dibujo tendrá importantes consecuencias para la valorización del patrimonio cultural, patrocinada por las aristocracias y burguesías europeas; y en la voluntad de devolverlo a las masas, como efecto del poder de las clases dominantes.

El artículo analiza cómo esta revolución y la promoción de las artes caseras implicaron: i) una ideación de un patrimonio nacionalista, apoyada por un movimiento internacional de países; ii) una certificación, por las aristocracias europeas, de las llamadas grandes artes, para servir de inspiración para el trabajo del taller; iii) el comienzo del tema del patrimonio cultural como fenómeno de las masas populares; iv) la eventual ruptura del valor de autenticidad de las piezas artísticas.

Palabras clave: Joaquim de Vasconcelos; Arte y ciencia aplicados a la industria; Patrimonio cultural; Educación técnica.

\section{INTRODUÇÃO}

O historiador e pedagogo português Joaquim de Vasconcelos ${ }^{1}$ (18491936) foi um defensor apaixonado da convicção progressista no ensino do desenho, que se instalou em diversos países europeus, com repercussão nas Américas, durante a segunda metade do século XIX - no contexto da disputa europeia por uma supremacia industrial e dos produtos industriais nacionais. $\mathrm{O}$ forte investimento no ensino do desenho devia redundar no aperfeiçoamento técnico e moral dos alunos destinados aos ofícios, na criação de escolas artísticas, de museus anexos às escolas ou na organização de exposições temáticas. Devia redundar numa instrução popular orientada para a indústria e comércio, no desenvolvimento das artes e das ciências aplicadas às indústrias e na posse de uma cultura geral ao alcance de todos, que autorizasse os consumidores a reconhecerem nos produtores a tenacidade, a diligência e a arte dos seus produtos.

O favorecimento de uma educação artística industrial iria intercetar um outro aspeto preponderante no século XIX, a proteção da herança cultural pelos países, percebida como um bem coletivo. A leitura de um

\footnotetext{
1 O seu nome era Joaquim António da Fonseca de Vasconcelos.
} 
conjunto de textos selecionados da obra de Joaquim de Vasconcelos permite-nos discutir quer a relevância das formas de industrialização das artes oficinais (para as classes operárias) quer a dos meios de reprodução técnica dos modelos (para as classes aristocráticas assegurarem a proteção da sua herança). Os meios de reprodução iriam difundir, como nunca anteriormente, os protótipos dos objetos e monumentos dos países, e valorizá-los como recurso didático. Joaquim de Vasconcelos dedicou-se ao estudo da história portuguesa para tentar estabelecer os parâmetros autênticos e vernaculares das artes oficinais da sua pátria e descrever a genealogia de uma arte nacional, que deveria ser devolvida e ensinada a artistas e operários. Por outras palavras, o estudo persistente e continuado deveria apurar uma herança cultural resistente a toda a prova.

A ideia de herança cultural (ou de património cultural), em construção durante o século XIX, sobretudo nos países da Europa ocidental, era considerada como a soma de um conjunto de vestígios monumentais e de objetos artísticos. Durante essa época constituinte ela alicerçava-se nos meios de reprodução para se expandir e tornar-se apropriável pelas massas populares, como usufruto, e pelos alunos-operários, como matéria de trabalho; e defrontava, ao mesmo tempo, a erosão provocada pela disseminação e pela replicação, isto era, a erosão de uma metamorfose que o pensador alemão Walter Benjamin interpretou como a perda de autenticidade da herança cultural. É como construção histórica e didática que tentamos demarcar, no pensamento de Joaquim de Vasconcelos (com o auxílio do de Benjamin) o que nos coube das relíquias como herdeiros do presente, e do seu valor e entendimento.

\section{A FORJA DOS NOVOS OPERÁRIOS E AS INDÚSTRIAS CASEIRAS}

O estímulo para a criação e o desenvolvimento de uma classe operária instruída, hábil, organizada, especializada e conhecedora da herança cultural foi um dos propósitos mobilizadores da vida do historiador e pedagogo português Joaquim de Vasconcelos. O projeto de uma especialização profissional para que os jovens portugueses da segunda metade do século XIX pudessem tornar-se operários qualificados e escapar à miséria requeria uma sólida aprendizagem, que tinha como modelo experiências internacionais, centradas na combinação entre instrução primária e instrução profissional (na ligação entre escola elementar 
e oficina). Essa aprendizagem significava usar métodos racionais que fossem compreendidos como princípios educativos e o abandono dos caprichos e gostos individuais. As experiências internacionais modelares eram maioritariamente provenientes de França, Inglaterra, Áustria e Alemanha.

A experiência francesa do fomento do ensino popular baseava-se no conhecimento de que o trabalho manual seria o destino da maioria das crianças da classe operária. Fundava-se numa oferta estatal de instrução dirigida às crianças pobres, centrada no aperfeiçoamento das habilidades oficinais, no desenvolvimento do gosto pelo trabalho e numa aprendizagem técnica e moral dos ofícios. Um dos aspetos mais relevantes era a ambição de fazer dos jovens operários artistas, isto era, de os tocar com a bênção de o trabalho utilitário e necessário à subsistência poder ser, também, um amor da arte pela arte. Joaquim de Vasconcelos apoiou-se na obra do inspetor-geral do ensino primário profissional em França, Gustave Salicis, que reivindicava para os jovens alunos a procura do entendimento das origens dos ofícios, o conhecimento de uma "genealogia do trabalho ${ }^{2}$ e o exercício, para o tornar pertinente, de «faculdades inventivas». ${ }^{3}$ Era preciso pagar um preço para que esses progressos se concretizassem: o ensino puramente intelectual tinha de ser encurtado e não podia exceder os 13-14 anos de idade, de modo a encaminhar os filhos do povo o mais cedo possível para o manejo dos ofícios, assegurando-lhes uma sólida formação. Previa-se, era verdade, que o chamado ensino especulativo pudesse ser completado mais tarde pelos artistas-operários, através da frequência dos cursos noturnos.

A aquisição do hábito e do gosto em trabalhar seriam incorporados pelo contacto com os materiais e pelo fabrico de peças simples, já que a realização do trabalho concreto constituiria uma força de atração, com o seu benefício material crescente. O currículo para uma aprendizagem manual satisfatória juntava à instrução primária já existente o estudo, o conhecimento e a manipulação de matérias-primas; a prática de fabrico de peças na bancada, no torno ou na forja como primeira especialização;

\footnotetext{
2 Gustave Salicis, «Enseignement primaire et apprentissage» [O ensino primário e a aprendizagem nos ofícios, trad. Joaquim de Vasconcelos, $4 .^{\circ}$ artigo], Revista da Sociedade de Instrução do Porto I (4), (1881): 126.

3 Salicis, «Enseignement», 128.
} 
a prática do desenho, «a arte de traduzir corretamente uma ideia» e o "pensamento» dos jovens operários, ${ }^{4}$ nas suas múltiplas formas: «relevo, modelação, moldagem, escultura em pedra mole, em mármore e em madeira. Desenho gráfico e aguadas»; 5 elementos de escrituração e economia; o traçado, invenção e execução de peças; o ensino dos requisitos morais e o ensino da ordem: «A ordem na própria pessoa, a ordem nos instrumentos, no trabalho, na oficina, na escrituração, a ordem no espírito e, portanto, no comportamento», regulados pela atenção pedagógica do mestre. ${ }^{6}$

Joaquim de Vasconcelos defendeu continuadamente o desenvolvimento das chamadas indústrias caseiras: um conjunto vasto de ofícios manuais (tecidos, cerâmica, madeiras, metais, etc.), sem necessidade de um grande aparato técnico para prosperar, sem necessidade de fábricas, de capitais avultados e de matéria-prima estrangeira. Estas indústrias retomariam uma tradição manufatureira-artística com séculos de existência, de que se tinha perdido a ligação histórica, com o termo da transmissão e aperfeiçoamento anteriores do saber na convivência entre aprendizes, oficiais e mestres nas oficinas. As escolas profissionais organizadas pelo Estado, para além do estímulo ao progresso das classes operárias e à manutenção dos ofícios tradicionais, jogavam um papel relevante na consolidação da herança cultural da nação, pela manutenção das tradições manufatureiras, a partir dessa destreza tecnológica-moral descrita por Gustave Salicis.

As indústrias caseiras só podiam prosperar se várias condições fossem cumpridas: i) uma reforma do ensino do desenho, já que as ideias artísticas elementares eram moldadas pelo domínio do desenho; ii) a criação de escolas de arte aplicada às indústrias (ou escolas de artes industriais, como também eram chamadas); iii) a criação de museus de arte industrial; iv) a criação de coleções artísticas com uma forte componente histórica-didática; v) e o desenvolvimento da investigação histórica sobre a genealogia das indústrias artísticas. «As indústrias são mil, cada uma tem condições especiais de desenvolvimento, cada uma tem

\footnotetext{
${ }^{4}$ Gustave Salicis, «Enseignement primaire et apprentissage» [O ensino primário e a aprendizagem nos ofícios, trad. Joaquim de Vasconcelos, $7 .^{\circ}$ artigo], Revista da Sociedade de Instrução do Porto II (1), (1882): 10.

${ }^{5}$ Salicis, «Enseignement» [6. ${ }^{\circ}$ artigo], I (12),: 382-383.

${ }^{6}$ Salicis, «Enseignement» [6. ${ }^{\circ}$ artigo], I (12),: 383 e [7. ${ }^{\circ}$ artigo], II (1),: 20.
} 
sua história; mas essa história não está estudada entre nós; a tradição não pode, pois, falar, e como ela não fala, não se conhecem as condições em que as indústrias floresceram entre nós».7 Para transformar em indústrias de trabalho racional e concorrencial essas mil indústrias caseiras, de feição e ornamentos ingénuos ou primitivos, sem propriamente um funcionamento de mercado, e cujos produtos circulavam apenas para adornar as casas ou os próprios objetos caseiros, era absolutamente necessário instalar um meio de ensino, as escolas de arte aplicada.

O desenho era a disciplina central de que dependiam todos os ofícios manuais, como tinha demonstrado em primeiro lugar a Inglaterra, depois da sua experiência falhada de potência industrial na primeira grande exposição internacional (Londres, 1851). «Em tudo o que a mão tinha de continuar o trabalho da máquina, nobilitando-o e idealizando-o por assim dizer, se conheceu a inexperiência quase infantil, a rotina, o mau gosto, a inferioridade numa palavra». ${ }^{8}$ A partir da experiência inglesa (mas também da alemã) presumia-se que o ensino do desenho devia preceder mesmo o ensino da leitura e da escrita, mas não de qualquer desenho: o dos objetos mais familiares para as crianças como treino de observação e de perceção. A Inglaterra reconheceria a muito insuficiente educação das classes laboriosas e, numa temática que o historiador português considerou determinante, não fez da reforma de academias de estudos superiores nem de "programas pomposos» a sua preocupação central: «Atacou o mal pela raiz e tratou logo de reformar radicalmente o ensino do desenho em todas as suas escolas».$^{9}$

\section{O EXEMPLO DE SOUTH KENSINGTON}

Logo em 1852, criou-se o Museu de South Kensington (atual Museu Victoria \& Albert). Nascido com o nome de Museu das Manufaturas na residência real Marlborough House, cedida pelo príncipe Alberto, reinstalou-se em 1854 no bairro de Brompton, numa propriedade adquirida

\footnotetext{
7 Joaquim de Vasconcelos, A reforma do ensino de belas-artes III. Reforma do ensino de desenho seguida de um plano geral de organização das escolas e coleções de ensino artístico com os respetivos orçamentos (Porto: Imprensa Internacional, 1879), XIX.

8 Joaquim de Vasconcelos, "A reforma do ensino do desenho. Introdução», O Ensino. Jornal do Colégio Portuense dedicado aos pais I (1), (1877): 2.

9 Vasconcelos, «A reforma do ensino do desenho. Introdução», 2.
} 
com os lucros da primeira grande exposição internacional e sob os auspícios do príncipe. Foi então que adquiriu o nome de South Kensington e o apelido Albertopolis, vindo a abrir as portas ao público em 1857 (compunha-se do edifício do Museu e de uma galeria construída para sedear uma coleção de pinturas oferecidas por um particular). Tal como Joaquim de Vasconcelos descreveu, os ingleses tinham feito o balanço de criação da Escola-mãe de Design fundada em 1837 em Somerset House e das duas dezenas de escolas de design provinciais (não exatamente de desenho) criadas até 1851, revelando a quase total ausência de uma educação preparatória.

A reformulação do sistema britânico de ensino artístico, baseado numa cooperação entre Estado e iniciativa privada, determinou inicialmente a fundação de uma escola de formação de professores e de um museu para a instrução artística geral em Londres, a cargo do governo; e de escolas e classes de arte locais um pouco por todo o país. A aquisição de objetos de arte provenientes da grande exposição internacional de 1851 formaria o núcleo inicial de uma coleção sistematizada de artes fabris (tecidos, metais, cerâmicas, vidros, mobiliário, etc.) para fins educativos.

As escolas locais de arte podiam pedir o empréstimo de objetos a Marlborough House (entre julho e setembro) e comprar peças excedentárias ou duplicados. Segundo as memórias de Henry Cole, membro principal do comité encarregado de comprar obras de arte na exposição de 1851 e primeiro diretor do Museu de South Kensington (a partir de 1857), o núcleo museológico inicial foi rapidamente aumentado, com aquisições de espécimes de manufaturas de todas as épocas pagas pelo Estado, além de empréstimos da rainha, do príncipe Alberto e de colecionadores. Ao mesmo tempo, iniciou-se a reprodução de peças que estavam temporariamente no museu, através da fotografia, da execução de moldes e da galvanoplastia, ${ }^{10}$ na sequência de exposições organizadas com peças emprestadas. ${ }^{11}$

\footnotetext{
${ }_{10}$ Processo técnico de reprodução de objetos a partir da criação de moldes, usando uma resina e colocando os moldes numa tina juntamente com o metal com que se quer fazer a reprodução. As partículas do metal fixam-se no molde por eletrodeposição, através de corrente elétrica, até se formar uma camada metálica que reproduz o objeto.

${ }^{11}$ Henry Cole, Alan S. Cole e Henrietta Cole, Fifty years of public work of Sir Henry Cole. Accounted for in his deeds, speeches and writings (London: George Bell and Sons, 1884), 279-289.
} 
Cole assinalou a grande relevância da reprodução de peças para o desenvolvimento do museu e para os museus locais que se iam formando - situação que decorria já da atividade anterior do Museu de South Kensington; e que recebeu um forte impacto com a Convenção para promover universalmente a reprodução de obras de arte em benefício dos museus de todos os países, durante a Exposição de Paris (1867), assinada por governantes do Reino Unido da Grã-Bretanha e Irlanda, Prússia, Grão-Ducado de Hesse, Reino da Saxónia, França, Bélgica, Rússia, Reinos Unidos da Suécia e Noruega, Itália, Áustria e Dinamarca. O pequeno texto da Convenção afirmava que a facilidade de reprodução de monumentos e peças artísticas por diversos meios, sem danos para os originais, e o seu conhecimento para o progresso da arte, resultavam em elementos de grande valor para a instrução pública e para os museus a ela associados. Lembrava que o início da reprodução de peças artísticas tinha começado no Museu de South Kensington, de tal modo que os visitantes da Exposição de Paris em 1867 tinham podido contactar com objetos de arte ingleses, celtas, hindus, suíços, russos, germânicos, italianos, franceses, espanhóis e portugueses.

Sob o beneplácito real e adotando uma proposta de Henry Cole, a nova organização inglesa deixava cair a Escola de Design, «cujo nome levaria a uma má-interpretação» para a reformular com o nome de Departamento de Arte Prática, sob uma divisão com três propósitos: instrução elementar de desenho e de modelagem; aprendizagem prática do fabrico das artes; cultivo da relevância do design..$^{12}$ Essa organização concentrar-se-ia na criação de escolas elementares de desenho com a missão de fazer constar os elementos da arte e da ciência na educação pública; na criação de um corpo profissional para escolas de arte aplicada; e no desígnio de uma «educação do senso artístico» dirigida à população através da abertura de museus públicos de arte aplicada. ${ }^{13}$ Tratava-se de uma instrução de caráter científico-artístico, já que eram tão importantes a escola normal de Museu de South Kensington, as coleções, os museus e escolas locais, como o domínio científico de um conjunto de disciplinas. ${ }^{14}$

\footnotetext{
12 Cole, Cole e Cole, Fifty years of public work, 296.

13 Vasconcelos, «A reforma do ensino do desenho. Introdução», 3.

14 Geometria, desenho de máquinas, construção civil e naval, mecânica teórica e aplicada, magnetismo e eletricidade, química, geologia, mineralogia, fisiologia, fisiologia das plantas, botânica, zoologia, metalurgia, minas e fornos (Vasconcelos, A reforma do ensino de belas-artes III, 4).
} 
O desenvolvimento das indústrias da arte jogar-se-ia, portanto, na formação de artífices-artistas e, simultaneamente, na formação do gosto de um público que reconhecesse a «verdadeira arte», isto era, poder apreciar a «beleza da forma, a simetria das proporções, a simplicidade da natureza». ${ }^{15} \mathrm{~A}$ Inglaterra tinha então criado duas categorias de ensino artístico: «667 Art-classes» e "144 Schools of art», à última das quais pertencia a de South Kensington. ${ }^{16}$ A lição que a Inglaterra mostrava ao mundo, segundo o historiador português, e particularmente a Portugal, era a de que o centro da atenção estava na escola elementar e não nas escolas superiores e secundárias e muito menos nas academias de belas-artes.

\section{MUSEU AUSTRÍACO APROXIMA AS ARTES MENORES E AS ARTES MAIORES}

A importância pedagógica ganha pela experiência austríaca obrigava a conhecer e valorizar os três tipos de estabelecimentos em que o ensino do desenho era professado e a quem ele se dirigia: para além da Escola Superior e Geral de Arte Aplicada (a Escola de Viena anexa ao Museu Austríaco, que superintendia como escola central e como representante do grau de ensino mais elevado do desenho), havia as escolas de ofícios e as escolas de arte aplicada. As escolas de ofícios (apenas oito, localizadas nos grandes pontos industriais do Império) dirigiam-se ao aperfeiçoamento técnico das classes operárias; as escolas especiais de arte aplicada (39, na contabilidade feita por Joaquim de Vasconcelos no final da década de 70 do século XIX) estavam disseminadas pelo território austríaco, procurando desenvolver a aptidão operária onde quer que ela se encontrasse e intensificar as capacidades educativas pelos lados técnico e estético. A existência destas escolas especiais de arte aplicada permitia localizar um conjunto de atividades artísticas «elementar, espontâneo, individual»,17 que se mantinham ao longo de séculos como sustento de milhares de famílias, e permitia avivá-las e desenvolvê-las.

Por Museu Austríaco entendia-se a existência de uma série de instituições: um museu, uma escola superior de arte aplicada à indústria,

\footnotetext{
15 Vasconcelos, «A reforma do ensino do desenho. Introdução», 3.

16 Vasconcelos, A reforma do ensino de belas-artes III, 118-119.

17 Vasconcelos, A reforma do ensino de belas-artes III, 70.
} 
a biblioteca do museu, três ateliês do museu (moldagem de gessos, ${ }^{18}$ galvanoplastia e fotografia) e o Instituto Experimental Químico-Técnico - este último para que as descobertas científicas mais inovadoras se pusessem ao serviço das indústrias artísticas (trabalhos de cerâmica, vidro e esmalte).

Uma das fisionomias mais valiosas do Museu Austríaco era a forma como concebia a constituição de coleções. Na impossibilidade de adquirir objetos de arte originais das indústrias da arte, foram mobilizados os objetos artísticos da Corte Imperial, da nobreza e da burguesia rica para que pudessem fazer-se cópias que os três ateliês (moldagem de gessos, galvanoplastia e fotografia) transformaram no inventário o mais completo possível dos tesouros artísticos da nação; e numa importante fonte de receitas pela venda de reproduções em gesso, fotografias e galvanoplastias que, em breve, estavam a ser adquiridas por vários museus europeus. Essas coleções incluíam a indústria têxtil, trabalhos de verniz, esmaltes, mosaicos, pinturas, artes gráficas e impressão, produção de livros, objetos de couro, vidro, cerâmica, madeira, chifre, ouro e marfim, metal, ferro, bronze, ourivesaria e bijutaria, gravuras e cunhos, desenhos ornamentais e escultura de grandes dimensões (arquitetónica e ornamental).

A coleção de gravuras ornamentais (gravuras para servir de modelos na ornamentação de objetos de arte industriais) recortava-se entre todas pelo número (cerca de 14 mil folhas em 1879), pela variedade (representação das escolas alemã, francesa, flamenga e italiana), pela cronologia (séculos XV a XVIII) e pelo que representava com tudo isso - um grande arquivo de arte ornamental.

A Escola Superior de Arte Aplicada austríaca era também modelar do ponto de vista do ensino do desenho e na definição dos limites e variações entre esse ensino nas escolas de arte aplicada e na Academia de Belas-Artes de Viena. Recrutava o conhecimento das «artes maiores»

\footnotetext{
18 «De entre todos os materiais didáticos destinados ao ensino artístico são, sem dúvida, os denominados "gessos" aqueles que mais se associam à imagem que se transporta de uma academia de arte, possuindo as mais famosas destas instituições de ensino verdadeiras galerias destas reproduções, realizadas em formas, das mais famosas e marcantes obras de escultura clássica. Os "gessos" resultavam de uma escolha dos exemplares originais, fundamentando-se essa seleção nas regras e princípios do classicismo" (Maria Helena Lisboa, As academias e escolas de belas artes e o ensino artístico (1836-1910) (Lisboa: Edições Colibri e IHA, 2007), 281.
} 
para a formação dos alunos-artesãos, suscitando uma autonomia do saber desses alunos com destino à invenção. Fixava a ideia de que a arte industrial constituía a essência das três artes da pintura, da escultura e da arquitetura, aplicada às exigências da vida moderna - como se lia em parte de um relatório oficial traduzido por Joaquim de Vasconcelos ${ }^{19}$ - e que a formação de um artista se devia fazer tanto a partir do saber da arquitetura e da construção como da invenção e decoração interiores, num ecletismo que não dispensava ourives, oleiros, ferreiros e bronzistas de terem sólidos conhecimentos arquitetónicos se queriam dar aos seus objetos um cuidado cunho artístico.

O Museu Austríaco tinha servido de modelo para a criação de equipamentos semelhantes em Munique, Dresden, Leipzig, Berlim, Estugarda, Karlsruhe, Hamburgo e em uma dúzia de outras cidades alemãs. ${ }^{20}$ As referências alemãs eram tidas em boa conta por Joaquim de Vasconcelos, nomeadamente os métodos do ensino elementar do desenho e a formação de professores de desenho. Sobressaía, pela sua exemplaridade, o Museu de Leipzig, um equipamento municipal sem paralelo em qualquer instituição portuguesa de âmbito nacional, com reproduções de coleções artísticas completas. "Oferece, pois, o que nenhum museu da Europa, ainda o mais rico, pode dispensar ao estudioso: os documentos práticos da história da arte, sem lacunas, sem pontos de interrogação, sem saltos, e ainda a vantagem da confrontação, do agrupamento por afinidade, da sintetização!».21

Em Portugal, o desenvolvimento das artes aplicadas às indústrias deveria organizar-se por certos tipos fundamentais nas grandes cidades e por especializações conformes às pequenas indústrias locais. $\mathrm{O}$ modelo português não deveria ter o «alto caráter artístico» ${ }^{22}$ do austríaco - querendo dizer-se que a escola central anexa ao Museu Austríaco se aproximava mais de uma academia de belas-artes do que no modelo inglês, nomeadamente quanto à importância do ensino de arquitetura, escultura e pintura na formação dos artistas em arte industrial aplicada.

\footnotetext{
19 Vasconcelos, A reforma do ensino de belas-artes III, 110.

20 Vasconcelos, A reforma do ensino de belas-artes III, 9 e 121.

21 Vasconcelos, A reforma do ensino de belas-artes III, 164.

22 Vasconcelos, A reforma do ensino de belas-artes III, 120.
} 
Ou seja, numa ligação vital e mais intensa entre as artes industriais e a «arte erudita»-, pois basear-se-ia nos elementos tradicionais das províncias e na capacidade de sustentar as indústrias caseiras ainda latentes, que estariam a ponto de desaparecer perante a concorrência internacional e as novidades que iriam chegar pelas vias de comunicação, como o caminho-de-ferro. «Urge acudir-lhes enquanto se não extinguem de todo pela viação acelerada que lhes vai levar em breve, com as novas linhas férreas, os produtos mais baratos (de caráter totalmente diverso e que hão de seduzir pela novidade) das indústrias estrangeiras».23

Sob este ponto de vista, havia uma clara filiação de Joaquim de Vasconcelos nas correntes internacionais do movimento que viria a denominar-se Arts \& Crafts, e uma crítica radical ao empobrecimento trazido pela produção industrial em massa e pelas condições de trabalho que se anunciavam sob esse paradigma. O que deveria fazer-se sem demora, portanto, era "perscrutar a vida passada das nossas indústrias», ${ }^{24}$ era uma geografia artístico-industrial do país, mapeando as indústrias históricas extintas ou a extinguir-se em breve, para que as escolas de arte aplicada a criar pudessem ser rigorosamente localizadas. Joaquim de Vasconcelos propunha museus provinciais e escolas anexas de primeira classe em oito cidades portuguesas (que comparava com as 39 austríacas e as 144 inglesas), a partir do aproveitamento de certa especialização industrial lusa.

Joaquim de Vasconcelos constatava que o ensino elementar do desenho era obrigatório nas escolas primárias dos países liderantes na Europa e não esquecia que era necessária a preparação de mestres de desenho. De acordo com o sistema inglês, a prática do desenho - que era uma formação e, ao mesmo tempo, uma edificação moral - deveria ser feita de três modos: desenho de memória (cópias e objetos), feito sobre objetos e estampas; desenho de invenção, sobre a composição com os elementos já aprendidos; e desenho a tempo fixo (sobretudo cópias), que tinha por finalidade educar um golpe de vista rápido e seguro, desenvolver o sentimento das qualidades caraterísticas do objeto no aluno e «combater a indolência em geral». ${ }^{25}$

\footnotetext{
${ }^{23}$ Vasconcelos, A reforma do ensino de belas-artes III, 120.

${ }_{24}$ Vasconcelos, A reforma do ensino de belas-artes III, 193.

25 Vasconcelos, A reforma do ensino de belas-artes III, 16.
} 
No seu diagnóstico, o abandono do ensino do desenho por parte do governo português tinha produzido a total pobreza de ideias artísticas, que viviam da imitação e do plágio generalizados. O desenho, "fundamento indispensável de todo o ensino artístico, fundamento em que a Europa trabalha há mais de um século» era tratado em Portugal como «bagatela». ${ }^{26}$ Não havia, na sua pátria, escolas de desenho elementar ou ensino do desenho para tecelões, ourives, oleiros ou marceneiros, oficinas para a aprendizagem dos ofícios, não havia museus nem bibliotecas tecnológicas ou museus históricos com peças originais (ou com reproduções).

Nem vontade, do seu ponto de vista, de satisfazer condições mínimas de proporcionar o desenvolvimento do ensino profissional: «O que pedimos é apenas: muito desenho, um pouco de gesso, e um pouco de abnegação da parte de todos, em proveito do país». ${ }^{27}$ A falta de uma boa aprendizagem era a principal causa do estado de decadência da indústria portuguesa, sem a qual método e ordem científicos na oficina eram impossíveis de obter - um dado histórico que este autor, como também Gustavo Salicis, via na quebra do antigo sistema das artes oficinais em que aprendizes, oficiais e mestres das oficinas se relacionavam. $\mathrm{O}$ sistema antigo, à custa de privilégios e restrições, garantia, no entanto, a realização de exames que aferiam as capacidades dos aprendizes e a graduação obrigatória da aprendizagem. A desagregação desse laço teria gerado o descrédito da aprendizagem, as deserções nas oficinas - os jovens operários saíam e entravam ao sabor da sua lassidão - ou a impreparação total dos operários quando lá chegavam, não se chegando a substituir o antigo regime por outro ensino.

\section{ARTÍFICES, ARTÍFICES-ARTISTAS, ARTISTAS}

Se as aptidões técnicas tradicionais se podiam manter no tempo, com o apoio do governo às indústrias caseiras, as escolas profissionais de aprendizagem deviam organizar-se a partir de duas figuras preponderantes: oficiais hábeis no manejo dos instrumentos de trabalho e dos instrumentos da respetiva indústria; e bons mestres de desenho conhecedores

\footnotetext{
26 Joaquim de Vasconcelos, A Reforma do Ensino de Belas-Artes II (Análise da segunda parte do relatório oficial) (Porto: Imprensa Literário-Comercial, 1878), XI.

${ }_{27}$ Vasconcelos, A reforma do ensino de belas-artes III, XXI.
} 
de princípios de modelação e de bons modelos para o desenho - nunca perdendo de vista um objetivo central, a constituição de uma coleção de modelos de estampas e gessos, a preços acessíveis. "Um oficial hábil no manejo dos instrumentos de trabalho, conhecedor do material da respetiva indústria; um bom mestre de desenho, que conheça os princípios da modelação, e uma escolha acertada de bons modelos para o desenho» seria tudo o que era necessário para a organização de uma escola profissional de aprendizagem, além de uma «coleção de modelos, composta de estampas e gessos, [que] pode fazer-se nas condições mais económicas». 28

O que estava subjacente a uma tal organização de ensino, de formação de coleções ou de preservação dos modelos culturais de uma nação era a ligação da "arte erudita» com as artes industriais, a educação dos artistas com o horizonte nas grandes artes - pintura, escultura e arquitetura -, de tal forma que os artífices que quisessem ser mais do que artífices se afastassem do vulgar produto do seu ofício. Este aspeto era mais particularmente visível no caso da Áustria, já que o modelo inglês fazia da pintura um auxiliar da ornamentação, da escultura um auxiliar da modelação e da arquitetura sobretudo desenho arquitetónico. «E contudo os resultados da escola inglesa não são em nada inferiores aos da austríaca».29

O historiador português considerava o progresso no trabalho das artes e ofícios relacionado com três estádios, técnicos e de aquisição de uma consciência: os artífices constituíam o grupo que se ocupava de um ofício «onde a arte não tem aplicação»; os artífices-artistas eram o grupo que aplicavam «a arte à sua indústria»; os artistas eram o grupo que cultivava a grande arte, «a arte que subsiste de per si» e o seu fim utilitário como desígnio ideal. ${ }^{30}$

A avaliar pelo melhor exemplo europeu, o austríaco, a «arte erudita» e as artes industriais viviam uma ligação indesmentível e os artistas

\footnotetext{
${ }_{28}$ Joaquim de Vasconcelos, «Educação popular. Sobre o ensino profissional por parte das associações e do Estado», Revista da Sociedade de Instrução do Porto II (2), (1882): 52.

29 Vasconcelos, A reforma do ensino de belas-artes III, 118.

30 Joaquim de Vasconcelos, "A reforma do ensino do desenho V (O regulamento oficial austríaco)», O Ensino. Jornal do Colégio Portuense dedicado aos pais I (9), (1878): 68.
} 
não poderiam ser educados nas artes industriais sem conhecimentos que pertenciam à arquitetura, à pintura e à escultura. Mas este modelo não significava subtrair a importância do ensino superior artístico nas academias de belas-artes, antes se obtinha protegendo a autonomia funcional do ensino das escolas de arte aplicadas. Estas deviam educar ornamentistas e desenhadores, por exemplo, como artistas dedicados às necessidades das indústrias artísticas, sob o princípio da união entre grande arte e artes industriais.

Ancorado na perspetiva de que a arte provinha da indústria da arte, Joaquim de Vasconcelos reclamou para Portugal museus de arte industriais e escolas de aplicação antes de academias e de museus de academias (estas últimas mais próximas de uma instrução em que as elites se reproduziam, pelas possibilidades de acesso). No conjunto diversificado de artigos que escreveu em publicações ao longo de décadas, envolvia o conhecimento de historiador de arte com a verve de publicista, disparando frequentes vezes em direção aos desejos mais íntimos de manutenção dos privilégios do saber das elites portuguesas, em favor da educação artística.

«É preciso que a arte seja o pão quotidiano de todos e que esse pão seja barato e de fácil digestão; académicos de alto coturno seriam pedantes neste caso». ${ }^{31}$ As academias de belas-artes existentes no país, em Lisboa e no Porto, não tinham nem influência nem tão pouco um conhecimento sobre a circulação das ideias artísticas ou sobre o ensino artístico. E não tinham certamente um ensino da arte aplicada às indústrias. «Nem uma faísca de sentimento estético achareis na minoria ilustrada, nem uma ideia pedagógica encontrareis no ensino que partisse dessas duas academias» [itálico do texto]. ${ }^{32}$

\section{PERTINÊNCIA DAS EXPOSIÇÕES E DAS COLEÇÕES MODELARES}

A primeira grande exposição em Portugal representativa da aliança entre arte e indústria, com um fim pedagógico e alcance nacional, segundo Joaquim de Vasconcelos, realizar-se-ia no Porto (1881), expondo de forma inaugural séries completas das artes industriais através dos

\footnotetext{
31 Vasconcelos, «A reforma do ensino do desenho. Introdução», 3.

32 Vasconcelos, A Reforma do Ensino de Belas-Artes II (Porto: Imprensa Literário-Comercial, 1878), VII.
} 
padrões e modelos que pudessem servir de exemplo aos artistas-operários, ligando o passado ao presente e relevando a necessidade de uma reforma do ensino técnico-artístico. A organização esteve a cargo do Centro Artístico Portuense, do qual Vasconcelos foi o primeiro presidente eleito - uma associação de ensino artístico livre fundada em 1880, que se propunha criar uma escola de desenho graduado e de modelação. «O ponto de vista pedagógico, que presidiu ao certame, determinou o seu aspeto original, característico» [itálico do texto], explicou Joaquim de Vasconcelos. ${ }^{33}$

A pedagogia indicaria os meios pelos quais as indústrias nacionais «em crise aguda», na imobilidade e na anarquia, apesar da abundância de matérias-primas, poderiam afirmar-se para além dos «expedientes do protecionismo ${ }^{34}$ estatal [itálico do texto], mudando a sua aplicação em função das necessidades locais. A exposição tinha uma parte retrospetiva, que permitia aferir a vitalidade de algumas das indústrias artísticas portuguesas antigas. "As obras de ourivesaria, os estofos, os bordados, as rendas, as obras de talha, os esmaltes, as iluminuras, etc., que ainda existem nas nossas igrejas e nas coleções públicas e particulares, aí estão para o provar». ${ }^{35}$

Para ter um sentido pedagógico, explicava o historiador, uma exposição artística necessitava apresentar a história completa de uma arte ou de uma indústria, sem grandes falhas e cujas peças provassem ser de «estilo puro»: «Só deste modo se pode estudar o desenvolvimento de um princípio artístico nas suas infinitas aplicações, a sucessão dos estilos, a sua mútua relação». ${ }^{36}$ As primeiras exposições industriais em Portugal tinham tido lugar na capital, Lisboa, em 1838, 1844, 1849 e $1863^{37} \mathrm{e}$ também no Porto $(1857,1861)$, que gozava da fama de ser «a primeira terra industriosa do reino, primeira pelos seus hábitos industriais e pelo

\footnotetext{
33 Joaquim de Vasconcelos, "A primeira exposição do Centro Artístico Portuense», Revista da Sociedade de Instrução do Porto I (7), (1881): 223.

34 Vasconcelos, «A primeira exposição», 223.

35 Vasconcelos, «A primeira exposição», 224.

36 Vasconcelos, «A primeira exposição», 225.

37 Carlos Loureiro, «O Museu Industrial e Comercial do Porto (1883-1899)», em Coleções de ciências físicas e tecnológicas em museus universitários: homenagem a Fernando Bragança Gil, coords. Armando Coelho Ferreira da Silva e Alice Semedo (Porto: Faculdade de Letras da Universidade do Porto, 2005), 190; Sociedade de Instrução do Porto, "Programa para a exposição de fiação e tecidos nacionais», Revista da Sociedade de Instrução do Porto III (12), (1884): 570.
} 
génio ativo e empreendedor dos seus habitantes».38 O Porto fundaria, de resto, "O primeiro templo consagrado à indústria portuguesa», 39 inaugurado no ano da primeira Exposição Internacional da Península Ibérica (1865), o Palácio de Cristal, dispondo de um grande salão para a exposição geral dos produtos industriais. Exposições de objetos artísticos teriam lugar em Lisboa $(1851,1858)$ e no Palácio de Cristal (Exposição de Arqueologia e de Objetos Raros Naturais Artísticos e Industriais realizada no Palácio de Cristal Portuense, 1867).

Sem possibilidade de apresentar uma série apenas com originais, que o próprio país não poderia custear mesmo que o desejasse, a exposição organizada pelo Centro Artístico Portuense, em 1881, recorreu a reproduções das indústrias de cerâmica, do vidro, têxtil, tipográfica, de tecidos, de bordados e rendas e de ourivesaria (quase mil estampas foram exibidas), demonstrando um pacto histórico entre artes e indústrias - «a aliança indissolúvel da arte com a indústria pela série ininterrupta de todas as indústrias» ${ }^{40}-$, com uma visão prospetiva do mundo contemporâneo e dos problemas laborais. Numa mostra que pretendia chamar a atenção para o modo como o ensino racionalmente organizado permitiria fazer reviver os elementos tradicionais da indústria portuguesa, essas estampas reproduziam coleções internacionais (da Áustria, da Prússia ou de Inglaterra) e originais e reproduções de obras de arte e de monumentos portugueses.

A Sociedade de Instrução do Porto organizou, também em 1881, uma exposição de gessos destinada a mostrar ao público uma coleção-modelo para o ensino do desenho que se debruçava não só sobre o material didático do ensino médio mas também do superior - esta circunstância era relevante em mais de um sentido ou não fosse a Academia de Belas-Artes de Lisboa responsável pela arrecadação e inventariação do património da nação ${ }^{41}$ e o estado de conhecimento do desenho em Portugal

\footnotetext{
38 Inácio de Vilhena Barbosa, «Palácio de Cristal no Porto», Arquivo Pitoresco. Semanário Ilustrado (1864): 2 .

39 Barbosa, «Palácio de Cristal», 2.

40 Vasconcelos, «A primeira exposição», 225.

41 Para além das competências relativas ao ensino artístico, a Academia de Belas-Artes de Lisboa era, desde a fundação em 1836, local de depósito de objetos provenientes de doações e de instituições diversas (nos anos 60 recebeu em depósito objetos de arte em metais preciosos provenientes da Casa da Moeda de Portugal que tinham origem nos conventos extintos do reino). Ao longo do século XIX
} 
não ser deplorável apenas no ensino elementar. Os alunos que demandavam as academias de belas-artes não possuíam a instrução elementar nem os que frequentavam o ensino profissional tinham a instrução geral preparatória ou a instrução elementar ou especial da disciplina que pretendiam continuar a desenvolver. ${ }^{42}$ Nas academias superiores, Vasconcelos tinha encontrado «não só pobreza mas desordem e falta de critério na escolha dos poucos objetos que ali foram ter - ao acaso». ${ }^{43}$

Ao acaso - é este o termo; gessos comprados a uns italianos ambulantes ${ }^{44}$, outros que um capricho qualquer de sorte trouxe para as lojas dos nossos livreiros, alguns poucos comprados a uma miserável indústria particular ou a outra indústria oficial ainda mais miserável ainda porque é paga com o dinheiro da nação e é um escândalo há 45 anos, eis os elementos que são fornecidos às aulas de desenho mais importantes do nosso país. ${ }^{45}$

\section{HERANÇA CULTURAL DAS ELITES PARA AS MASSAS}

Terá havido em Portugal o propósito de constituir uma grande coleção nacional de gessos, num contexto em que «as coleções de museus eram, mais do que nunca, uma extensão do ensino ministrado nas aulas [e] as coleções de reproduções eram seguramente os objetos que melhor encarnavam esta ambivalência de poder transitar entre os dois contextos».46 Apesar de algumas tentativas parcelares, a constituição de coleções do Estado sistemáticas, informadas e pedagógicas, que servissem os propósitos da instrução pública e, nomeadamente, as finalidades do ensino artístico industrial, não se fez.

\footnotetext{
teve um papel centralizador na arrecadação e musealização de objetos e na conservação dos monumentos.

42 Joaquim de Vasconcelos, A reforma de Belas-Artes. Análise do relatório e projetos da comissão oficial nomeada em 10 de novembro de 1875 (Porto: Imprensa Literário-Comercial, 1877), 10-11.

${ }_{43}$ Joaquim de Vasconcelos, «A exposição dos gessos do Liceu do Porto», Revista da Sociedade de Instrução do Porto I (8), (1881): 269.

${ }_{44}$ Alusão aos formadores italianos que tinham ganho protagonismo como intermediários entre os ensinos artístico e industrial, artífices altamente especializados que se espalharam pela Europa no século XIX (Cf. Ricardo dos Reis Mendonça, "A receção de escultura clássica na Academia de Belas-Artes de Lisboa» (Tese de Doutoram., Universidade de Lisboa, 2014), 118 e 129-130).

45 Vasconcelos, «A exposição dos gessos», 269.

46 Mendonça, «A receção de escultura», 109.
} 
A ausência em Portugal dessas coleções, representativas dos objetos das artes plásticas e das artes industriais europeias, de tal modo que os documentos da história da arte pudessem ser consultados sem hiatos, e pudessem ser confrontados para estudar as suas genealogias, contrastavam com um conserto europeu mais ou menos abrangente em favor da constituição de coleções, a que emprestavam o seu prestígio as mais altas figuras.

Na referida convenção internacional de 1867, as famílias reinantes da Europa determinavam ser seu desejo e vontade fomentar a reciprocidade entre nações para que, num esforço mútuo, comissões nacionais pudessem corresponder-se na troca de informação acerca das reproduções permutáveis; angariar reproduções de peças destinadas aos seus museus; e trocar objetos artísticos. Esses desejos reais apontavam para a relação entre dois «tempos históricos - nacional e universal», tornada pertinente com o engrandecimento do tempo da história, empurrado com as descobertas da arqueologia cada vez mais para trás e atualizado face ao passado próximo cada vez mais em direção ao presente, «à medida que os estados-nação emergentes buscavam preservar e tornar imemorial a sua própria formação como parte do processo de "nacionalizar" as suas populações». ${ }^{47}$

A troca internacional de cópias de objetos artísticos raros, a compra de objetos artísticos e de modelos de estudo e a importância estratégica dos inventários dos tesouros artísticos das nações, todas essas ações tiveram origem nos dirigentes pertencentes à realeza dos países, bem coadjuvados pelas burguesias abastadas. Desta forma, os seus objetos e monumentos de prestígio ficavam preservados, passando a constituir um património cultural e serviam de modelo ao trabalho dos alunos-artífices. Não era apenas porque estes alunos podiam aprender arquitetura, escultura e pintura nas escolas de arte aplicada (que também preparavam para o estudo nas academias) que as "produções artísticas superiores» se encontravam com os ofícios, e que a «arte erudita» se misturava com as artes industriais; era, evidentemente, porque os modelos para copiar e para servir de inspiração e influência eram os das realezas, das cortes imperiais, da alta aristocracia e da burguesia rica.

\footnotetext{
47 Tony Bennett, «The exhibitionary complex», New Formations. A Journal of Culture, Theory \& Politics 4 (1988): 89.
} 
Esses eram os modelos que materializavam o que se entendia por alta cultura. Joaquim de Vasconcelos explicava isso mesmo, ao manifestar-se a favor da constituição de coleções artísticas por meio de reproduções em Portugal, já que as obras originais de grande valor artístico estavam, em finais dos anos 70 , em coleções públicas inalienáveis ou em poder de milionários e «as antigas coleções de casas reinantes ou principescas passaram a ser ou propriedade das nações ou propriedade inalienável».48

A «arte erudita» para todos era, pois, uma apropriação pelas classes laboriosas dos modelos e padrões das aristocracias e realezas, intensificada e valorizada por uma formação técnica de grande nível. A nacionalização das coleções aristocráticas, por um lado, e a destreza e aptidões dos operários, por outro, fariam convergir esses mundos separados nas bancadas e nas forjas das oficinas de trabalho. E o estudo profundo das indústrias caseiras faria emergir os influxos das tradições nacionais mais genuínas.

A compulsão perseverante de documentos em vários arquivos tinha permitido a Joaquim de Vasconcelos descobrir nas artes portuguesas elementos constituintes estrangeiros e o aproveitamento de outros como nacionais, a partir da esquematização das relações internacionais de Portugal nos séculos XV e XVI. Tal investigação permitia-lhe afirmar que, pelos movimentos de mercadores ou pela localização de feitorias, era possível traçar o movimento de obras de arte e as influências artísticas da arte nacional.

O movimento internacional em torno da educação artística sugeria, portanto, uma apropriação dos valores estéticos das classes dominantes pelo trabalho laborioso das classes fabris, em que o valor de autenticidade das peças se jogava em dois tabuleiros: por um lado, essa autenticidade correspondia aos modelos impostos por quem encomendava, pagava e trocava as obras de arte; por outro, originava a procura de um conhecimento histórico e do estudo aturado da genealogia das coleções artísticas e das suas proveniências, prática a que Joaquim de Vasconcelos se ofereceu com galhardia, para ser adaptado e encaminhado para as artes caseiras.

48 Vasconcelos, A reforma do ensino de belas-artes III, 160. 


\section{NA ENCRUZILHADA DO VALOR DE AUTENTICIDADE}

Numa conferência já em pleno século XX (1915), Joaquim de Vasconcelos lembrou à plateia os "recursos gráficos incomparáveis» ${ }^{49}$ que permitiam improvisar facilmente pequenos museus com boas reproduções. Recordou que o Museu de South Kensington tinha sido o modelo de museu de arte industrial como princípio de uma boa pedagogia estética - que todos os aglomerados populacionais até cinco mil habitantes deveriam pensar em adotar como museu popular de arte. Em Portugal, só as duas cidades mais importantes tinham tido acesso a museus mais ou menos nessas condições, ficando a província longe de qualquer desenvolvimento.

Ao encontrar-se na convergência entre a necessidade de constituir elementos didáticos para os alunos e a sua relevância para a realização de inventários artísticos, as coleções de objetos orbitavam uma questão que a manutenção dos ofícios tradicionais e das tradições artísticas seculares do trabalho oficinal (e a examinação do respetivo sistema de ensino) punham em relevo - e que ligava a tendência evolutiva da arte às condições da sua reprodução massiva industrial: a questão da autenticidade dos objetos de arte.

A crer em Walter Benjamin, a autenticidade das obras de arte manterse-ia se reproduzidas manualmente (poderíamos dizer: no torno ou na forja) mas não se reproduzidas tecnicamente (um monumento ou objeto artístico abandonaria o seu lugar para figurar num suporte destinado a servir de modelo aos alunos, descobrindo-se perspetivas e ângulos que, de outra forma, não seriam acessíveis). «A autenticidade de uma coisa é a suma de tudo o que desde a origem é transmissível, desde a sua duração material ao seu testemunho histórico».50 É, como afirmou, «o aqui e o agora da obra de arte - a sua existência única no lugar em que se encontra»,51 ligada a um contexto histórico cultual, pois as obras de arte tinham surgido ao serviço de uma função ritual. Esse aqui e agora, essa autenticidade, seria a soma da fabricação de uma peça e da sua história

\footnotetext{
49 Joaquim de Vasconcelos, "Conferência (28 de janeiro de 1915)», O Instituto. Revista Científica e Literária 63 (1916): 292.

${ }^{50}$ Walter Benjamin, «A obra de arte na era da sua reprodutibilidade técnica», em Sobre Arte, Técnica, Linguagem e Política (Lisboa: Relógio D’ Água Editores, 1992), 79.

${ }^{51}$ Benjamin, «A obra de arte», 77.
} 
depois dela, até chegar a nós. Seria uma soma de materialidade, durabilidade e testemunho histórico.

Na reprodução técnica, ausentar-se-ia o testemunho histórico (Benjamin diz que «ele acaba por vacilar»), ${ }^{52}$ ausentar-se-ia a essência da obra de arte, aquilo a que Benjamin chamou aura. "Definimos esta última como manifestação única de uma lonjura, por muito próxima que esteja». ${ }^{53}$ A libertação do domínio da tradição far-se-ia através de uma perda, abalada pela atualidade permanente das reproduções. Esta análise diria que estava a subtrair-se da herança cultural o valor de tradição, isto era, o contexto em que obras de arte tinham adquirido o seu valor original, autêntico. As obras de arte estariam numa multiplicidade de suportes e as técnicas de reprodução conferiam aos objetos uma atualidade permanente.

Um ritmo acelerado da técnica dissolveria a "autêntica tradição».54 Mas do que constaria ela? Walter Benjamin tornou claro que para ser «autêntica», essa tradição se inscreveria num tempo histórico descontínuo, pois «a tradição é o descontínuo do que já foi, por contraste com a história enquanto contínuo de acontecimentos». ${ }^{55}$ Ao divisar esse tempo descontínuo, os historiadores estariam aptos para desmantelar as épicas conceções de uma história universal e empática com os vencedores da história, e aptos para fixar no passado os olhos incandescentes do presente.

O historiador volta costas ao seu próprio tempo, e o seu olhar de vidente inflama-se com os cumes dos acontecimentos de gerações humanas anteriores, progressivamente mais mortiços à medida que vão mergulhando mais no passado. Este olhar de vidente tem do seu próprio tempo uma consciência mais nítida do que os contemporâneos que «acompanham» esse tempo. ${ }^{56}$

Esse ser inatual face ao contemporâneo seria o que reclamava o resultado final do trabalho perseverante e contínuo de Joaquim de Vasconcelos,

\footnotetext{
52 Benjamin, «A obra de arte», 79.

53 Benjamin, «A obra de arte», 81.

54 Walter Benjamin, O anjo da história (Lisboa: Assírio \& Alvim, 2010), 157-158.

55 Benjamin, $O$ anjo da história, 158.

56 Benjamin, O anjo da história, 159.
} 
quando viajava aos séculos anteriores para historiar as formas artísticas da nação. Elas deviam constituir-se em formas genuínas, é certo, mas não heroicas para engrandecimento da nação a qualquer custo. Ora, se para ser apropriada pelas massas populares contemporâneas, a herança cultural deixava os seus lugares de origem e informava os povos sobre a arte que devia constituir um património, formando os operários para lidar com esse património, ela tendia a inscrever-se nos objetos resultantes dos saques e das batalhas (e de algumas aquisições), e num contínuo histórico que falava das conquistas e das vitórias dos dominantes, através da valorização dos seus objetos de prestígio.

De um certo ponto de vista, a herança cultural perdia o valor da tradição e podia ser apreendida pelas massas, dado que os objetos e monumentos que a constituíam tinham abandonado o lugar de origem, designadamente para serem reproduzidos nas coleções que serviam para a aprendizagem dos alunos-operários ou para figurarem nos museus de réplicas. Os alunos lidavam com os modelos da herança cultural, não com a singularidade deles. E certamente não já com o mundo cultual de onde as obras originais tinham sido apeadas. Pois o que se transmitia aos alunos não era a dimensão cultual da herança, mas a forma reprodutível dela, que as aristocracias entenderam conceder para permanecer como classes dominantes.

No manejo da herança cultural, os alunos podiam ter a experiência fabril mas não a experiência da autenticidade - ou, tendo em conta que os seus modelos eram réplicas, a sua experiência de autenticidade era diferida; no manejo dos materiais e das formas, tinham a experiência da autenticidade (o aqui e o agora) mas não a da lonjura, pois os artefactos que fabricavam não podiam ser considerados património, pelo menos não naquela altura em que estavam a ser construídos (esses artefactos, se tivessem sobrevivido, poderiam vir a constituir um património cultural nosso contemporâneo, por exemplo como exemplares de um museu didático das experiências fabris passadas).

Mesmo do ponto de vista de Joaquim de Vasconcelos, que estudava e relacionava para conhecer a autenticidade das tradições artísticas com o fim de as devolver aos aprendizes como modelos, essa devolução não implicaria, coincidentemente com a fabricação oficinal, o desvanecimento da própria tradição de que seriam testemunho? Pois a reprodução 
das peças artísticas apresentava-se menos como testemunho histórico, embora escondessem uma historicidade, do que como testemunho de um ensino, de uma pedagogia e de um mercado, ou seja, como uma forma de oferecer ao público uma herança cultural.

Apesar de tudo, a pretensão de conceber obras de arte dirigidas às massas, conquistando o seu público, designadamente pela instrução dos seus artífices e pela exposição em museus (como a Inglaterra tinha preconizado logo a partir do fiasco de 1851), essa pretensão fundava-se nas tradições artísticas dos tesouros secularmente acumulados. Era, portanto, o valor da tradição (que Walter Benjamin via esfumar-se nos objetos) que Joaquim de Vasconcelos, entre outros historiadores, afirmava como emancipador do trabalho industrial para uma nova geração de artistas-operários: «Os nossos reformadores e legisladores entenderam em geral poder prescindir nas suas reformas dos elementos que a tradição [itálico do texto] lhes legara; destruíram quase sempre para construir de novo, podendo tantas vezes limitar o trabalho a uma reconstrução, com proveito para todos». ${ }^{57}$

No íntimo da questão situar-se-ia a relação entre mestres e aprendizes no contexto oficinal e a aquisição de uma sólida aprendizagem. Se a reprodução das peças artísticas era mais um testemunho de ensino do que um testemunho histórico, a relação oficinal baseava-se na experiência sustentada por um saber antigo, tal como os modelos a usar na confeção das peças artísticas. "Na verdade, de que nos serve toda a cultura se não houver uma experiência que nos ligue a ela?». ${ }^{58}$ Dar-se à experiência, movimentar-se nessa aprendizagem, partir dos modelos culturais reprodutíveis para entender neles a antiguidade da sua proveniência e a possibilidade da sua contemporaneidade, movimentar-se num contexto em que as palavras dos mestres indicassem um saber, que se não oferecesse à indigência, que não propagasse a pobreza (na relação entre mestre e aprendizes, nas formas a executar), era esse o propósito de uma sólida aprendizagem que transformaria operários em fazedores de objetos artísticos.

Só o ato de os aprendizes de artistas poderem imergir no movimento do tempo presente para se ausentarem temporariamente da atualidade de massas os tornaria aptos para apreender o autêntico. É verdade que

\footnotetext{
57 Vasconcelos, A reforma de Belas-Artes, 55.

58 Benjamin, O anjo da história, 74.
} 
essa experiência, na forma de uma ausência temporária do atual, isto era, na forma da aquisição do conhecimento da tradição sustentada pelo estudo histórico, não deveria subjugar-se a todos os vestígios que as aristocracias acumularam, nem a todas as relíquias com que as burguesias preencheram, por acumulação, os vazios existenciais.

E não deveria apenas cravar-se no passado, como se não houvesse um mundo novo a abrir-se; a herança cultural que seria devolvida às massas poderia ser assimilada sob essas formas de vestígios aristocráticos e relíquias burguesas; mas na bancada e na forja, enquanto estivessem a ser trabalhados os modelos, enquanto houvesse uma experiência e uma metamorfose a decorrer, eles deviam sofrer das mãos dos operários o influxo que os entregaria para consumo, quem sabe, como peças artísticas de um futuro experimental.

A herança cultural, passada pelo cadinho da experimentação, devolvida ao público sob a forma de produtos artesanais provenientes de uma experiência oficinal, saída das mãos dos artistas-operários, não podia ser confundida com a herança cultural para usufruto do mesmo público; a primeira era um trabalho idealmente baseado num trabalho empírico enraizado em tradições seculares, por um lado, e em modelos e padrões das classes superiores, por outro; a segunda era um efeito do trabalho que podia ser apreendida pelas massas como tentativa de aproximação a um gosto requintado; a primeira era uma experiência, a segunda o usufruto da experiência; a primeira comunicava o propósito da produção, a segunda a ideia do consumo.

\section{VISITANTES COMO ESPETÁCULO DOS MUSEUS}

Intelectuais como Joaquim de Vasconcelos estudaram a fundo o nascimento, estabelecimento e progresso das artes tradicionais para propor uma alteração paradigmática na criação e na receção das peças artísticas. Para que o trabalho da arte fosse valorado, a criação e a receção buscavam um fundamento nas tradições históricas dos movimentos artísticos e nas especificidades nacionais de cada país, as quais deviam ser minuciosamente estabelecidas.

Dessa nova criação e receção eram peças-chave os museus. "Os museus deveriam ser, entre nós, museus para as artes industriais, primeiro 
que tudo, único modo de serem úteis, praticamente, imediatamente».59 A organização então existente em Portugal era criticada por Joaquim de Vasconcelos, em primeiro lugar porque eram poucos os museus existentes; em segundo lugar porque não preenchiam o fim didático que deviam cumprir, fazendo-se sem plano, método ou fim prático; e, em terceiro lugar, em consequência desses factos, porque se ofereciam à mera fruição. «Servem hoje apenas para deleite dos olhos; não satisfazem, no mais mínimo, o sentimento estético, porque neles se acham aglomerados e colocados, promiscuamente, objetos que destoam uns dos outros». ${ }^{0}$

O surgimento de museus exibindo peças artísticas estava relacionado com a existência de outros espaços (museus de ciência e de história natural, dioramas, galerias comerciais, montras de lojas, exposições internacionais), e com a divulgação de um conhecimento proveniente da emergência de disciplinas novas (biologia, antropologia, arqueologia). $\mathrm{O}$ «complexo expositivo» que se tinha destacado da primeira grande exposição internacional de 1851, em que técnicas de exibição ordenavam, simultaneamente, os objetos a serem vistos e os espetadores que os viam, «teria uma influência profunda e duradoura no desenvolvimento subsequente de museus, galerias de arte, exposições e lojas comerciais». ${ }^{61}$ O complexo expositivo assim definido agregava as multidões que convocava "fazendo da multidão o espetáculo final»,62 ao mesmo tempo que regulava os seus fluxos. Joaquim de Vasconcelos não se referia a esse dispositivo, endereçado ao público para efeitos de fruição e de consumo, que apresentava uma herança cultural para ser suficientemente exposta ao alcance dos curiosos e destinada a ser frugalmente explicada. Referia-se, claramente, aos museus didáticos, ordenados para estudo e conhecimento da história das peças, aos museus enquanto locais de trabalho e de experimentação.

O abandono dos objetos colocados um pouco ao acaso (como nos antigos gabinetes de curiosidades e nos museus didaticamente desordenados), em favor de uma racionalidade em que imperava a ordem, a

\footnotetext{
59 Vasconcelos, A reforma de Belas-Artes, 20.

60 Vasconcelos, A reforma de Belas-Artes, 20.

61 Bennett, «The exhibitionary complex», 74.

62 Bennett, «The exhibitionary complex», 81.
} 
separação e a classificação, parecia conferir aos museus o fundamento didático que eles necessitavam para se separarem da sua pré-história, referida como caótica, isto era, anticientífica. Mas era porque os museus se compreendiam como mais uma das instituições educadoras dos estados modernos, desejando abrir-se às massas, que eles estavam a abandonar a função didática nos termos em que Joaquim de Vasconcelos a expunha. E estavam a abandonar, necessariamente, a ligação da herança cultural a uma experiência vivida, de que falava Walter Benjamin.

Ao instituir o deleite dos visitantes como objetivo, os museus estavam a convidar multidões para os visitar (desde que de forma ordeira e sóbria) e estavam a abandonar, definitivamente, quer a ligação às escolas de formação quer à prática artística, que Joaquim de Vasconcelos tinha proposto na sua contemporaneidade. Ao abandonar a ligação à prática e à pedagogia para se instituírem como lugares de mera fruição, os museus sinalizaram, como nenhuma outra instituição, a necessidade de criar a devida distância em relação aos operários-estudantes, às manufaturas artísticas e às práticas artísticas - restava visitá-los para usufruir de um deleite popular constituído pelos produtos acabados dessas aventuras oficinais e fabris anteriores.

\section{CONSIDERAÇÕES FINAIS}

A luta pelo estabelecimento de uma escola, de um ensino e de um estudo criteriosamente organizados para fazer despontar da sua letargia o ensino profissional em Portugal deveria, segundo o historiador Joaquim de Vasconcelos, concorrer para uma mudança social de grande alcance, à semelhança de experiências internacionais com o mesmo propósito: retirar da miséria, da fome e da indolência milhares de jovens destinados aos ofícios manuais. Um tal propósito baseava-se na reforma do ensino do desenho, a base de todo o trabalho manual em maior ou menor grau, e na certeza, expressada em várias ocasiões pelo historiador-pedagogo, de que as indústrias caseiras só sobreviveriam se fossem sustentadas pelos conhecimentos histórico e científico, de modo a que as tendências artísticas de que seriam representantes se afirmassem como escolas, sob uma tradição segura e secular.

O fomento da arte industrial, arte aplicada ou arte decorativa, como se lhe quisesse chamar, requeria que todos os esforços se concentrassem 
nas escolas elementares de desenho, que deviam ser fortemente influenciadas pelas experiências inglesa e austríaca, e não nas academias de estudos superiores; na disponibilização de material ilustrativo de ensino, em particular compêndios (nos quais as questões metodológicas eram centrais), em coleções de ensino artístico, formadas por meio de reproduções, e na criação de museus, submetidos à pedagogia do ensino profissional.

A educação de artistas-operários, a formação de coleções de ensino artístico e a criação de museus de arte aplicada às artes e ciências, além de permitir uma ligação das chamadas artes «maiores» às artes industriais, tiveram uma repercussão decisiva na preservação dos modelos culturais das elites europeias, ou seja, na constituição de patrimónios nacionais. Descidos do seu pedestal, esses patrimónios estavam ao alcance das massas de alunos para poderem ser trabalhados na bancada ou na forja, e ao alcance das massas de visitantes e curiosos para poderem ser testemunhados e contemplados.

A herança cultural, assim reconhecida e suscetível de ser replicada muito para além do seu local e contexto de origem, sofria por essa disseminação uma rotura com o seu fabrico, significado e destino iniciais. Essa rotura, identificada por Walter Benjamin como a perda de autenticidade, teria para historiadores como Joaquim de Vasconcelos o mérito de possibilitar uma apropriação do conhecimento da história da arte pelos ofícios manuais e de poder desenvolver um sentimento nacional de pertença: só se a história fosse estudada é que a tradição podia falar; ela só falaria desde que precedida por um laborioso trabalho de investigação-sistematização das condições de origem, fabrico e circulação dos padrões e modelos, que evidenciasse uma genealogia das ornamentações, com vista à construção de uma «pureza de estilo».63

O que seria essa genealogia, o que seria essa herança cultural, diferente da herança cultural que devia ser apropriada pelas massas e pelos visitantes de museus? A coleção de bens que correspondesse a uma tradição estabelecida pelo seu movimento perpétuo e permanente mudança, pela sua vivacidade (por exemplo, transformadora nas mãos dos alunos da instrução artística aplicada à indústria), de que só o estudo

${ }_{63}$ Vasconcelos, A reforma do ensino de belas-artes III, 42. 
aprofundado comprovaria as relações históricas e que, portanto, estaria sempre em trânsito, jamais sendo inteiramente instituída.

\section{Nota sobre o autor}

AnTónio HenRiques é investigador na Unidade de Investigação e Desenvolvimento em Educação e Formação, Instituto de Educação, Universidade de Lisboa (UIDEF/IE-ULisboa). Doutor em Educação, na especialidade de História da Educação pelo IE-ULisboa. Tem escrito sobre a relação entre a instrução pública e a herança cultural e sobre a construção da ideia de herança cultural nos debates parlamentares (século XIX). Integra o projeto coletivo (Re)Configurações do Ensino-aprendizagem e das Organizações de Ensino Superior num Contexto de Mudança.

\section{REFERÊNCIAS}

Benjamin, Walter. «A obra de arte na era da sua reprodutibilidade técnica». Em Sobre Arte, Técnica, Linguagem e Política, 71-114. Lisboa: Relógio D’Água Editores, 1992.

Benjamin, Walter. O anjo da história. Lisboa: Assírio \& Alvim, 2010.

Bennett, Tony. «The exhibitionary complex». New Formations. A Journal of Culture, Theory \& Politics, no. 4 (Spring 1988): 73-102.

Lisboa, Maria Helena. As academia e escolas de belas artes e o ensino artístico (1836-1910). Lisboa: Edições Colibri e IHA/Estudos de arte contemporânea da Faculdade de Ciências Sociais e Humanas da Universidade Nova de Lisboa, 2007.

Loureiro, Carlos. «O Museu Industrial e Comercial do Porto (1883-1899)». Em Coleções de ciências físicas e tecnológicas em museus universitários: homenagem a Fernando Bragança Gil, coordenação de Armando Coelho Ferreira da Silva e Alice Semedo, 185-201. Porto: Faculdade de Letras da Universidade do Porto, 2005.

Mendonça, Ricardo Jorge dos Reis. «A receção de escultura clássica na Academia de Belas-Artes de Lisboa». PhD diss., Faculdade de Belas-Artes da Universidade de Lisboa, 2014. 